\title{
New methods of estimating the number of motor units in a muscle
}

\author{
H. S. MILNER-BROWN AND W. F. BROWN
}

From the Department of Clinical Neurological Sciences, University Hospital, London, Ontario, Canada

SYNOPSIS Two electrophysiological methods have been described for estimating the number of motor units (MU) in a muscle. The methods are based on the original methods of McComas and others, which involve dividing the maximum compound potential (MCP) of muscle evoked by supramaximal electrical stimulation of nerve by a mean motor unit potential (MMUP). The important modifications in the methods are the incorporation of the fluctuations in the response of MU to electrical excitation and a possible correction for the overlap in the firing levels of motor axons. The methods have been used in the estimation of the number of motor units in the first dorsal interosseous, thenar, hypothenar, and extensor digitorum brevis muscles of normal subjects and patients with various neuromuscular disorders. The results indicate that previous motor unit estimates were in general erroneously high.

In the preceding paper (Brown and MilnerBrown, 1976) it was shown that two of the most critical assumptions made in the electrophysiological method of estimating the number of motor units in a muscle introduced by McComas et al. (1971) were not correct. Modifications to the original method have recently been introduced by Ballantyne and Hansen (1974) and Panayiotopoulos et al. (1974), but both these two methods are influenced by the same two critical assumptions.

The first important factor in the estimation of the number of motor units in a muscle, which have so far been disregarded by the above authors, are inherent properties of motor axons: the fluctuations in their electrical excitability and their overlap in firing levels. The second important factor is that motor units whose sizes are much larger than the incremental steps evoked by nerve stimulation can be isolated by the isometric voluntary contraction method (Milner-Brown et al., 1973a), the F-recurrent discharge method (Brown and Feasby, 1974), and by stimulation of multiple points along the

\footnotetext{
1 Address for correspondence: Dr W. F. Brown, Department of Clinical Neurological Sciences, University Hospital, 339 Windermere Rd., London, Ontario N6G 2K3, Canada. (Accepted 10 October 1975.)
}

length of the nerve (Brown and Milner-Brown 1976). Hence, any motor unit estimate which excludes these properties of motor units cas generally lead to erroneous results. This papex describes two methods of estimating the number $\overrightarrow{0}$ of motor units in a muscle based on the originat or method of McComas et al. (1971), but with the important modification of incorporating the fluctuations in the response of motor units to electrical excitation and a possible correction for the overlap in motor axon firing levels.

\section{METHODS}

The basic method is unchanged and consists first in obtaining a mean motor unit action potential representative of the motor units in the muscle. The number of motor units is then estimated by dividing the maximum compound potential evoked in muscle by supramaximal electrical stimulation to the nerve by the mean motor unit potential (MMUP). The two methods to be described were developed at different times. The first method, which was more recently developed, has been used in the motor unit $\frac{T}{O}$ estimation (MUE) of mainly the first dorsal interosseous (1DI) muscle, but the second method has $N$ been applied extensively to the extensor digitorum brevis (EDB) and thenar and hypothenar muscles. The methods will be presented separately, followed by the basic biophysical principles justifying them. 


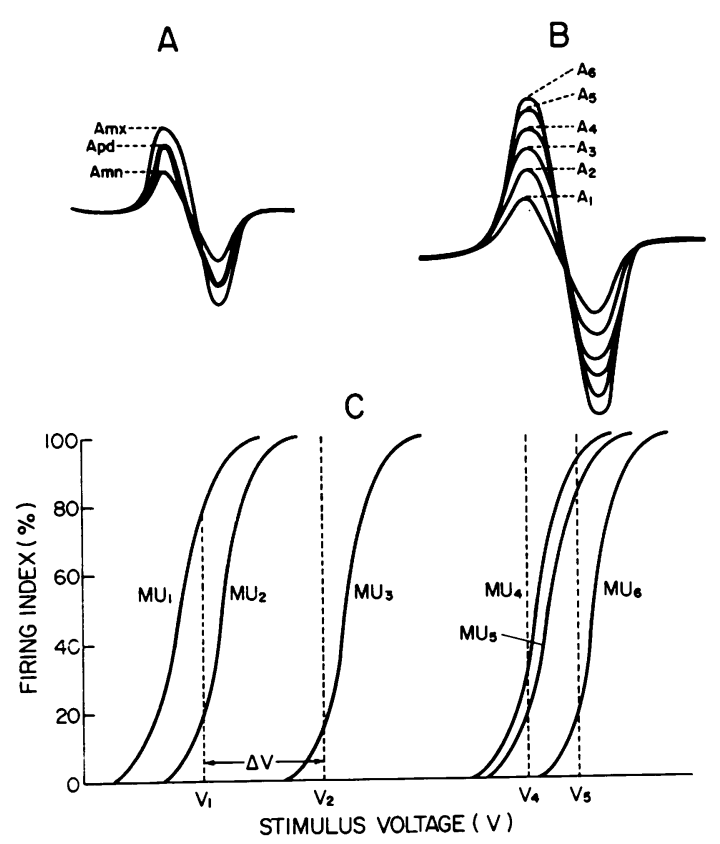

FIG. 1 Schematic diagrams to illustrate the fluctuations in excitability and overlap in firing levels of motor axons. A. At a constant voltage, the evoked potential can vary between a minimum $(\mathrm{Amn})$ and a maximum (Amx), but with the predominant potential (Apd). B. Incremental steps which can be attributed to the following factors: (1) the recruitment of additional motor units - if certain criteria are satisfied, (2) the fluctuations in the excitability of motor units, or (3) the overlap in firing levels of motor units. C. The increase in firing index from 0 to $100 \%$ with increasing voltage of six $M U$ and the overlap in firing levels of motor units $M U_{1}, M U_{2}, M U_{3}$ and $M U_{4}$, $M U_{5}, M U_{6}$.

METHOD I The subjects are comfortably seated and their hands and forearms are strapped to a padded board. Silver disc electrodes filled with conductive paste are placed on the belly of the IDI muscle with the indifferent electrode $3.0 \mathrm{~cm}$ away on the proximal joint of the second finger. The ulnar nerve is stimulated (Devices 3290, 3072) at the wrist by means of bipolar electrical pulses $0.1 \mathrm{~ms}$ in duration at $1 / \mathrm{s}$. The evoked potentials from 1DI are amplified by Grass P15 preamplifiers at a frequency bandwidth $30 \mathrm{~Hz}-10 \mathrm{kHz}$, displayed on an oscilloscope and stored on magnetic tape. The usual procedure is to increase the stimulus voltage gradually until the first motor unit is excited. The voltage is then fixed at this threshold voltage $\left(V_{1}\right)$ and 50 stimulus pulses applied to the ulnar nerve. The motor unit potential amplitude recorded from the muscle might vary between a minimum (Amn(1)) and a maximum $(\operatorname{Amx}(1))$. Between $A m x(1)$ and Amn(1) there may be other amplitudes; however, there is always a predominant amplitude (Apd(1)). Amx(1), Amn(1) and $\operatorname{Apd}(1)$ are noted (Fig. 1A).

The stimulus voltage is then gradually increased until an incremental step greater than $\operatorname{Amx}(1)$ is obtained. Fifty stimulus pulses are applied to the nerve at this voltage $\left(V_{2}\right)$ and $\operatorname{Amx}(2), A m n(2)$, and Apd(2) noted. Ten or more different voltages ( $\mathrm{Vn})$, with corresponding amplitudes $\operatorname{Amx}(\mathrm{n}), \operatorname{Amn}(\mathrm{n})$, $\operatorname{Apd}(\mathrm{n})$ are obtained. The procedure is repeated a number of times, and the maximum compound potential obtained, at the end.

In estimating the mean motor unit potential (MMUP), the main criteria for identifying the recruitment of an additional unit are that $\operatorname{Apd}(n+1)$ $>\operatorname{Apd}(n)$ and $\operatorname{Amn}(n+1) \geqslant \operatorname{Amx}(n)$ - that is, the predominant amplitude or area of the compound potential (CP) evoked by stimulating $n+1$ motor units is greater than the compound potential evoked by stimulating $\mathrm{n}$ motor units and also the minimum CP evoked by stimulating $n+1$ MU should equal or exceed the maximum CP evoked by stimulating $n$ MU with long train pulses and under the same experimental conditions. These criteria are based on the general assumption that if a stimulus voltage $V_{1}$ is required to recruit the first $\mathrm{n} M U$ and a higher voltage $V_{2}$ is needed to recruit the $(n+1)^{\text {th }} M U$, then $V_{2}$ should excite the same $n$ MU recruited at voltage $V_{1}$, plus the additional $(n+1)^{\text {th }} M U$, under the same experimental conditions. Thus it is evident from the above criteria that 10 incremental steps do not necessarily represent the recruitment of 10 motor units, but usually represent a fewer number of motor units. A justification of the criteria will be considered in the next section.

METHOD II The experimental arrangement used for MUE in EDB and thenar and hypothenar muscles has been previously described in detail (Brown, 1973). As the stimulus voltage is increased, 0-2 motor units with distinct thresholds may be recruited. After this number ( $n)$, any increase in stimulus voltage $(V)$, generally results in a fluctuation in the incremental steps ('alternation') as shown in the preceding paper. $\mathrm{V}$ is then kept constant and $\mathbf{5 0}$ stimulus pulses applied to nerve to produce $\mathrm{Nmx}$ incremental steps. The MMUP is estimated as follows: if the number of incremental steps with distinct thresholds-that is, firing points-is $\mathrm{n}$ (varies between 0 and 2 in normal subjects), then $\mathrm{Nmx}-\mathrm{n}$ steps were involved in the alternation. The maximum possible combinations of $\mathbf{N}$ motor units, with overlapping firing levels needed 
to produce $\mathrm{Nmx}-\mathrm{n}$ steps is given by $2^{\mathrm{N}}-1$. From the relation $2^{\mathrm{N}}-1 \geqslant N m x-n, N$ is found and the MMUP is computed by dividing the negative compound potential by the corrected number of motor units recruited, which is equal to $\mathrm{N}+\mathrm{n}$. The procedure is repeated a number of times, the negative MCP obtained, and the MUE calculated. The experimental justification of this method is presented by Brown and Milner-Brown (1976). A simple theoretical basis will be outlined in the next section.

JUSTIFICATION OF METHODS Method I Suppose the minimum voltage required to excite a motor unit is $\mathrm{V}$. If the voltage is kept fixed at $\mathrm{V}$, and 50 pulses given to nerve, the motor unit will fire only about $10 \%$ of the time - that is, response probability or firing index of $10 \%$. As the voltage is increased gradually, the firing index will increase until at voltage $\mathrm{V}+\triangle \mathrm{V}$, the firing index reaches $100 \%$. This fluctuation in excitability is an inherent property of animal and human axons (Blair and Erlanger, 1933; Pecher, 1939; Verveen, 1962; Ten Hoopen and Verveen, 1963; Bergmans, 1970; Brown and MilnerBrown, 1976). Figure 1C shows a schematic diagram of the firing index plots of six motor units. At a voltage $\mathrm{V}_{1}$, motor unit $\mathrm{MU}_{1}$ has a firing index of $80 \%$ and is represented by the potential $\mathrm{A}_{1}$ (Fig. 1B). Motor unit $\mathrm{MU}_{2}$ has a firing index of $20 \%$, indicated by an infrequent potential $A_{2} ; A_{2}$ may represent $\mathrm{MU}_{2}$ alone or $M U_{1}+\mathrm{MU}_{2}$. When the voltage is increased slightly (by $\triangle \mathrm{V}$ ) to $\mathrm{V}_{2}$, both $\mathrm{MU}_{1}$ and $M U_{2}$ will have a firing index of $100 \%$ and their sum may produce a predominant potential $\mathrm{A}_{3}$ and a less frequent potential $A_{4}$. If this happens, then $A_{2}$ cannot be counted as an incremental step, because it represents $\mathrm{MU}_{2}$ alone and not the sum $\mathrm{MU}_{1}+\mathrm{MU}_{2}$. In this situation, the incremental steps $A_{1}, A_{2}, A_{3}$ would represent the recruitment of two motor units and not three. In previous methods, $\mathrm{MU}_{2}$ could have been counted twice, which would decrease the MMUP, and hence overestimate the number of motor units.

Method II Figure 1C will again be used, but with the modification that $\mathrm{MU}_{1}, \mathrm{MU}_{2}, \mathrm{MU}_{3}$ are actually the first three units recruited and whose firing levels overlap less than $50 \%$. (In the Justification of Methods section (I) above, $\mathrm{MU}_{1}, \mathrm{MU}_{2}, \mathrm{MU}_{3}$ were not necessarily the first three motor units recruited, and their firing levels greatly overlapped). In this case, suppose there were no alternation until the voltage was $\mathrm{V}_{4}$ and motor unit $\mathrm{MU}_{4}$ and $\mathrm{MU}_{5}$ had FIs equal to $20 \%$ and $35 \%$ respectively. When 50 electrical pulses $\left(a t \mathrm{~V}_{4}\right.$ ) are given to nerve, $\mathrm{MU}_{4}$ and $\mathrm{MU}_{5}$ may fire separately to produce the incremental steps $A_{4}, A_{5}$ (Fig. 1B) or fire simultaneously to give a larger incremental step $\mathbf{A}_{6}$. This indicates that two motor units $\mathrm{MU}_{4}, \mathrm{MU}_{5}$ with overlapping firing levels can produce three incremental steps. When the voltage is increased to $\mathrm{V}_{5}$, an additional motor unit $\mathrm{MU}_{6}(\mathrm{FI}=20 \%)$ will be recruited and the three motor units can evoke a maximum of seven incremental steps from the possible combinations $\mathrm{MU}_{4}$, $\mathrm{MU}_{5}, \mathrm{MU}_{6}, \mathrm{MU}_{4}+\mathrm{MU}_{5}, \mathrm{MU}_{4}+\mathrm{MU}_{6}, \mathrm{MU}_{5}+$ $\mathrm{MU}_{6}, \mathrm{MU}_{4}+\mathrm{MU}_{5}+\mathrm{MU}_{6}$. From these two examples it can be deduced that $\mathrm{N}$ motor units with overlapping firing levels can generate $2^{\mathrm{N}}-1$ incremental steps. This is the theoretical basis of the method of correction for the overlap in motor axon firing levels, when calculating the MMUP. Direct experimental evidence and a more detailed quantitative treatment are given by Brown and Milner-Brown (1976).

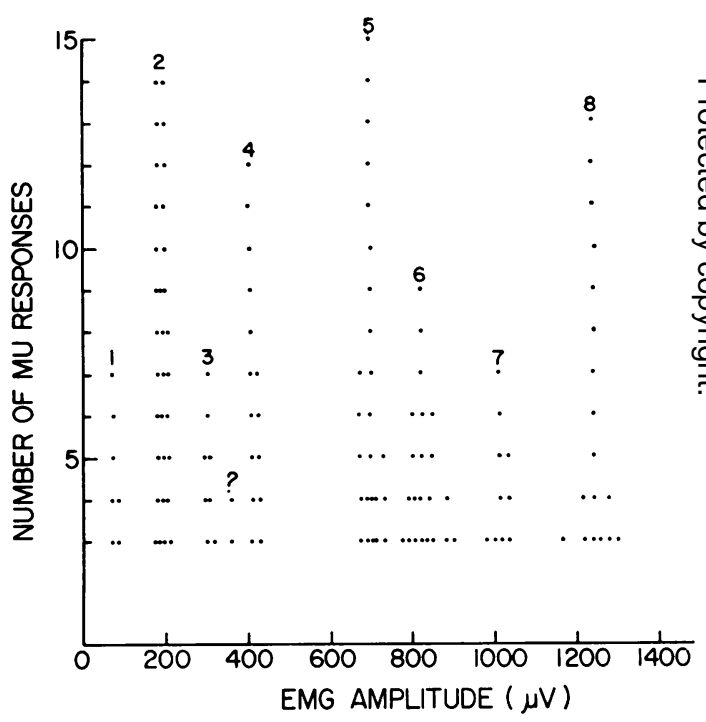

FIG. 2 Histogram of motor unit(s) responses to electrical excitation. At each stimulus voltage, 50 or more electrical pulses are applied to nerve. Each point represents the compound potential of a number of motor units evoked by a single electrical pulse. The 'groups', numbers 1 to 8 , represent the recruitment of single MU. These groups must satisfy the criterion $\operatorname{Amn}(n+1) \geqslant A m x(n)$. When there are uncertain groups (?) the MMUP will be calculated with and without the uncertain groups, and the resulting MUE will then lie within a range, usually less than $10 \%$ apart. The EMG amplitudes of the $M U$ recruited can be obtained from the peak or predominant amplitudes (Apd) in each group. The EMG amplitudes are ( $p-p)$ voltages. 


\section{RESULTS}

Method I was developed while electrophysiological studies were being carried out on IDI muscle. Silver disc surface electrodes $(9 \mathrm{~mm}$ diameter) filled with electrode paste were used, and signals amplified by Grass $\mathrm{P} 15$ preamplifiers (frequency bandwidth $30 \mathrm{~Hz}-10 \mathrm{kHz}$ ). In addition, the EMG parameters measured were $p-p$ amplitudes and areas. Method II, however, was applied to EDB and thenar and hypothenar muscles, using clip surface electrodes, and the EMG parameter measured was the negative peak amplitude. Non-commercial amplifiers at frequency bandwidth $1.0 \mathrm{~Hz}-1.0 \mathrm{kHz}$ were used. Because of these differences in measuring techniques, the results obtained using both methods will be presented separately.

METHOD I Motor unit estimates (MUE) were obtained from the 1DI muscles of 12 normal subjects and five patients with neuromuscular disorders between 20 to 40 years of age. Using the criteria for identifying the recruitment of an additional motor unit $(\operatorname{Apd}(n+1)>A p(n)$ and $\operatorname{Amn}(n+1) \geqslant \operatorname{Amx}(n))$, the compound potentials of 8-10 motor units were read directly from the storage oscilloscope: the MMUP, MCP, and hence MUE were computed. The results are presented in Table 1. The method was made more accurate by using a computer to calculate the peak-to-peak amplitude and areas of individual responses. A histogram of number of responses against peak-to-peak amplitudes and areas of motor unit potentials was plotted (Fig. 2). Each point represents the motor unit potential evoked by a single electrical pulse. A number of distinct peaks are evident, as well as a scatter of points at the base of each 'group'. The scatter of points around the base of each 'group' (the group refers to the vertical columns noticeable in the histogram) can be attributed to a number of factors. (1) At a stimulus voltage $\mathrm{Vn}, \mathrm{n}$ motor units recruited may be firing $100 \%$ of the time, giving rise to the predominant response in the group. However, if the $(n+1)^{\text {th }}$ and $(n+2)^{\text {th }}$ units have thresholds overlapping $\mathrm{Vn}$, they could be firing very infrequently, to produce the scatter in the motor unit potentials. (2) There can be a slight variation in the potentials of individual motor units evoked by a stimulus at constant voltage. (3) Mechanical factors such as movement of the stimulating electrode by even a fraction of a millimetre. In view of all these factors which contribute to the random fluctuation of motor unit potentials, the number of

TABLE 1

COMPARISON OF MEAN MOTOR UNIT POTENTIAL AND MOTOR UNIT ESTIMATE CALCULATED BY DIRECT MEASUREMENT (OSCILLOSCOPE) WITH CALCULATION BY COMPUTER

\begin{tabular}{|c|c|c|c|c|c|c|}
\hline \multirow[t]{2}{*}{ Subject } & \multicolumn{2}{|c|}{$M M U P(\mu V)$} & \multirow{2}{*}{$\begin{array}{l}M C P \\
(m V)\end{array}$} & \multicolumn{2}{|c|}{$M U E$} & \multirow[t]{2}{*}{ Comments } \\
\hline & Oscilloscope & Computer & & Oscilloscope & Computer & \\
\hline $\begin{array}{l}\text { HM } \\
\text { SB } \\
\text { HM } \\
\text { DM } \\
\text { JS } \\
\text { AH } \\
\text { SW } \\
\text { SW } \\
\text { CT } \\
\text { MJ } \\
\text { SY } \\
\text { SY } \\
\text { DZ } \\
\text { PB } \\
\text { KH } \\
\text { DM } \\
\text { RH }\end{array}$ & $\begin{array}{l}240 \\
220 \\
250 \\
233 \\
210 \\
250 \\
180 \\
200 \\
183 \\
200 \\
200 \\
220\end{array}$ & $\begin{array}{c}246 \\
266 \\
\\
230-254 \\
180-204 \\
190 \\
200 \\
155-175 \\
170 \\
190 \\
127-140 \\
440-508 \\
220 \\
480-533 \\
140\end{array}$ & $\begin{array}{c}29 \\
25.6 \\
29 \\
27 \\
31.9 \\
23.6 \\
25 \\
25 \\
18.4 \\
20 \\
24 \\
24 \\
16 \\
63.5 \\
16.4 \\
55.3 \\
14.7\end{array}$ & $\begin{array}{r}120 \\
116 \\
115 \\
116 \\
152 \\
95 \\
139 \\
125 \\
100 \\
100 \\
120 \\
110\end{array}$ & $\begin{array}{c}127 \\
109 \\
125-145 \\
115-130 \\
130 \\
125 \\
128-140 \\
140 \\
125 \\
114-125 \\
128-144 \\
75 \\
104-115 \\
105\end{array}$ & $\begin{array}{l}\mathbf{N} \\
\mathbf{N} \\
\mathbf{N} \\
\mathbf{N} \\
\mathbf{N} \\
\mathbf{N} \\
\mathbf{N} \\
\mathbf{N} \\
\mathbf{N} \\
\mathbf{N} \\
\mathbf{N} \\
\mathbf{N} \\
\mathbf{P} \\
\mathbf{M D} \\
\mathbf{M D} \\
\text { MD } \\
\text { MD }\end{array}$ \\
\hline
\end{tabular}




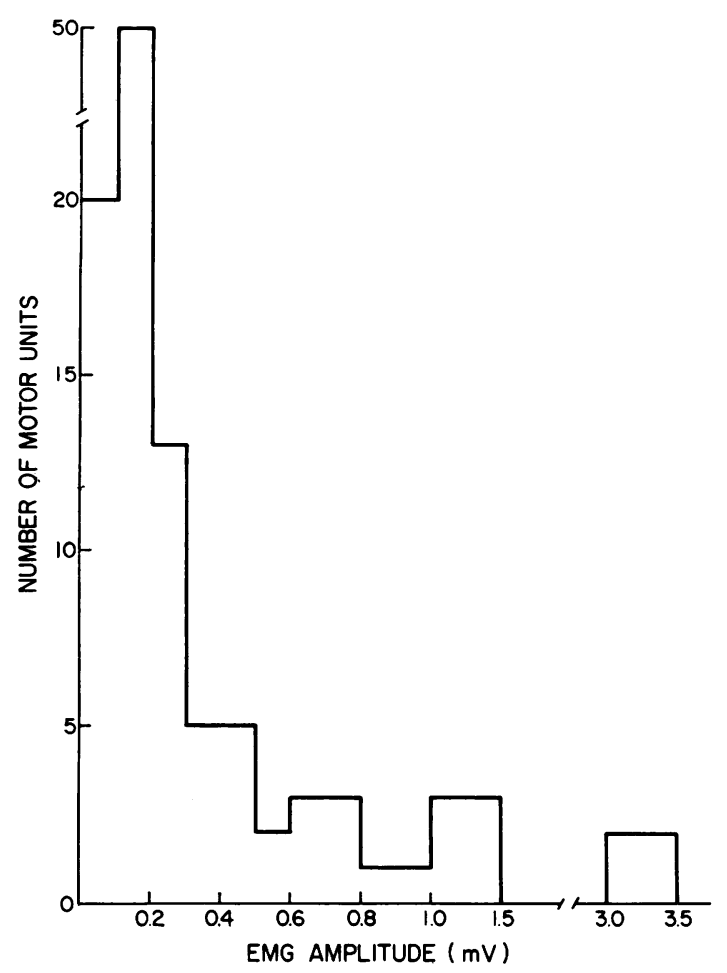

FIG. 3 EMG amplitudes of about one hundred MU obtained from the histograms (see Fig. 2) of 11 subjects. The amplitude of the $(n+1)^{\text {th }} M U$ recruited was obtained by subtracting the predominant amplitude of the previously recruited $n M U(A p d(n))$ from the predominant amplitude of the $(n+1)^{\text {th }}$ group Apd $(n+1)$. The EMG amplitudes are $(p-p)$ voltages.

motor units recruited are selected from the distinct peaks in the histogram (Fig. 2), which also satisfy the criterion $\operatorname{Amn}(n+1) \geqslant \operatorname{Amx}(n)-$ that is, the minimum evoked response of $n+1$ units should equal or exceed the maximum response of the same previously recruited $n$ units under the same experimental conditions. The results of this computation are shown in Table 1 , using only the amplitudes of motor unit potentials. At times when one or two groups are not distinct, the MMUP was calculated with and without the uncertain groups. In such cases the two estimated values of MMUP and MUE are both given in Table 1 . In the example given in Fig. 2, eight groups (numbered 1-8) are evident, in addition to one or possibly two indistinct groups. In this example, the MMUP will be calculated by dividing Apd (8), which is equal to $1250 \mu \mathrm{V}$, by 8 and 9 , to give $156 \mu \mathrm{V}$ and $139 \mu \mathrm{V}$ respectively. The MUE calculated from a maximum compound potential of $14.7 \mathrm{mV}$ will be in the range $94-105 \mu \mathrm{V}$. By reading the predominant (Apd) amplitude in each group the EMG amplitudes of the MU recruited can be directly obtained. (The EMG amplitude of the $(n+1)^{\text {th }}$ MU recruited is equal to $\operatorname{Apd}(n+1)-$ $\operatorname{Apd}(\mathrm{n}))$. As an example, the EMG amplitudes of the MU recruited in Fig. 2 are 75, 125, 100 , $100,290,115,195$, and $230 \mu \mathrm{V}$. The EMG amplitudes of about $100 \mathrm{MU}$ obtained from similar histograms of 11 subjects are shown in Fig. 3. The predominance of smaller motor units is similar to what was observed during isometric voluntary contraction (Milner-Brown et al., 1973a, b, c; Brown and Milner-Brown, 1976). Also, the presence of larger MU indicates that the samples of MU used in the calculation of the mean MU potential are reasonably representative of the total population of motor units.

METHOD II This method has been applied to 34 normal and 41 abnormal extensor digitorum brevis, hypothenar, and thenar muscles. The method is based on the experimental evidence that generally the firing levels of the first 3-10 motor units excited electrically overlap. The method then assumes that if $\mathrm{N}$ motor units with overlapping firing levels are excited by 50-100 electrical pulses at a constant voltage above their critical thresholds for firing, then it is highly probable that most or all of the possible combinations of $N$, given by $2^{N}-1$ will occur. Figure 4 is an illustration of how this method is used to estimate the mean MU potential. When the stimulus current was at $13.8 \mathrm{~mA}$, only a small MU (-ve peak $0.01 \mathrm{mV}$ ) was excited. The current was increased to $20 \mathrm{~mA}$ and a second MU was excited as shown in A. At $20.8 \mathrm{~mA}$ alternation occurred resulting in five incremental steps, indicated by the points on the graph and the evoked potential increments in the lower figure (B). From the relation $2^{\mathrm{N}}-1 \geqslant 5, \mathrm{~N}=3$ motor units produced the additional incremental steps. These three MU plus the first two MU with distinct firing points, would add up to five MU. Hence MMUP is obtained by dividing the compound potential in B by 5 not 7 .

In Fig. 5 a comparison is shown between the 


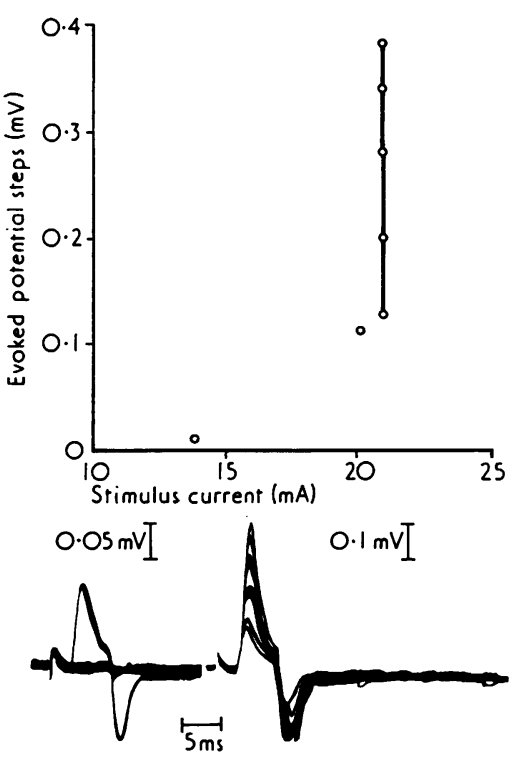

FIG. 4 Illustration of method II for measuring the MMUP. The upper graph is the negative evoked potentials recorded from the hypothenar muscles of a normal subject as the stimulus current was increased from 10-20.8 mA. The lower Figures A, B, are the actual evoked potential traces on the storage oscilloscope: A. shows the first two potentials at stimulus currents 13.8 and $20 \mathrm{~mA}(0.05 \mathrm{mV} / \mathrm{DIV})$ and $\mathrm{B}$ the combined potentials at $20.8 \mathrm{~mA}(0.1 \mathrm{mV} / \mathrm{DIV})$. Using the formula $2^{\mathrm{N}}-1$, the probable number of $M U$ involved in the five alternating steps would be three, and hence the total number of $M U$ which produced the compound potential $B$ would be three plus the first two $M U$ recruited.

conventional method of McComas et al. (1971) and the present 'alternation correction' method in the estimation of the MMUP. In the upper figure (A), six incremental steps were produced by graded electrical stimulation, and the MMUP calculated from the negative compound potential was $66 \mu \mathrm{V}$. In the lower figure (B), 100 stimulus pulses at motor threshold produced 15 incremental steps. By using the alternation correction formula $2^{\mathrm{N}}-1$, the probable number of $\mathrm{MU}$ to produce the observed 15 steps would be four, and the MMUP calculated equal to $100 \mu \mathrm{V}$. This comparison was done frequently in the initial stages, and it was found that the MUE using the alternation correction was, on average, $20 \%$ lower than the conventional MUE. In later

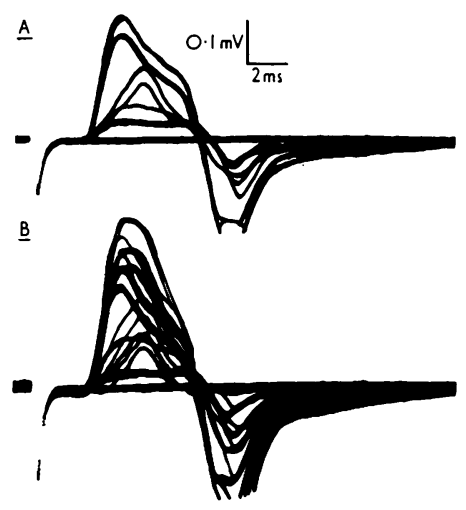

FIG. 5 A. Thenar MU potentials evoked by graded electrical stimulation to the median nerve. B. Evoked potential steps produced by 100 stimulus pulses at motor threshold. A close comparison betwen A and B, shows that some of the steps in $\mathrm{A}$ are the same as the steps produced in $\mathrm{B}$ as a result of alternation. The negative MMUP from A was $66 \mu \mathrm{V}$, while, using the correction formula $2^{\mathrm{N}}-1$, the MMUP from $\mathrm{B}$ was $100 \mu \mathrm{V}$.

stages of the investigation, the increasing awareness of the possibility of alternation led to the termination of the use of and the comparison with the conventional MUE. The alternation correction method has been used to estimate the number of motor units in extensor digitorum brevis, thenar, and hypothenar muscles of 34 normal subjects and 41 patients with peripheral neuropathies, predominantly pressure or entrapment neuropathies. The results are summarized in Table 2.

\section{DISCUSSION}

In the estimation of the number of motor units in a muscle, one is faced with a number of inevitable biophysical and experimental problems. However, the accuracy of the estimates depends significantly on how well the following important criteria are satisfied.

1. Do the incremental responses evoked by graded electrical stimulation correspond to the activation of single motor units? Because of the fluctuations in the excitability and overlap in firing levels of motor units, an incremental response does not necessarily correspond to the recruitment of an 
TABLE 2

MOTOR UNIT ESTIMATES USING METHOD II

\begin{tabular}{|c|c|c|c|c|c|c|}
\hline & \multicolumn{6}{|c|}{ Muscle } \\
\hline & \multicolumn{2}{|c|}{$E D B$} & \multicolumn{2}{|c|}{ Hypothenar } & \multicolumn{2}{|c|}{ Thenar } \\
\hline & Normal & Neuropathies & Normal & Neuropathies & Normal & Neuropathies \\
\hline $\begin{array}{l}\text { Mean } \pm \text { SD } \\
\text { Range } \\
\text { Number }\end{array}$ & $\begin{array}{c}163 \pm 84 \\
61-351 \\
10\end{array}$ & $\begin{array}{c}72 \pm 33 \\
33-131 \\
12\end{array}$ & $\begin{array}{c}300 \pm 125 \\
127-470 \\
10\end{array}$ & $\begin{array}{c}145 \pm 145 \\
20-545 \\
11\end{array}$ & $\begin{array}{c}261 \pm 116 \\
101-541 \\
14\end{array}$ & $\begin{array}{c}127 \pm 57 \\
6-206 \\
18\end{array}$ \\
\hline
\end{tabular}

additional motor unit. If two motor units $\mathrm{MU}_{1}$ and $\mathrm{MU}_{2}$ with overlapping firing levels are stimulated a number of times with above threshold stimuli, both $\mathrm{MU}_{1}$ and $\mathrm{MU}_{2}$ may fire simultaneously, or separately. The evoked responses may show three incremental steps, due to $\mathrm{MU}_{1}, \mathrm{MU}_{2}$, and $\mathrm{MU}_{1}+\mathrm{MU}_{2}$. This 'alternation' was recognized, but ignored, by the original authors (McComas et al., 1971; Sica et al., 1974). The two modified methods that have been decribed are attempts to solve the very important error of overestimating the number of motor units recruited in the first 10 or more incremental steps, using the conventional method of McComas et al. (1971).

The two methods evolved from experimental evidence on two inherent properties of motor units. Firstly, if the minimum voltage required to excite a motor unit is $\mathrm{V}$, then, over 50 trials, the firing index will increase from 0 to $100 \%$ as the stimulus voltage is increased from $\mathrm{V}$ to $V+\triangle V(\triangle V \doteqdot 0.05 V)$. Secondly, with the exception of certain neuromuscular disorders such as amyotrophic lateral sclerosis, in which the number of motor units is greatly reduced, the firing levels of even the first few motor units excited generally overlap. Considering the possible differences in the biophysical state of different motor units at any given time and mechanical effects such as electrode and limb position, it is very unlikely that two motor units will have coincident firing index versus voltage curves (excitability curves). This makes it possible to isolate distinct peaks as shown in the histogram in Fig. 2, representing the recruitment of single motor units, and helps to eliminate the possibility of counting a motor unit twice. The second method, however, depends on the theoretical and experimental data that, if $\mathrm{N}$ motor units with overlapping firing levels are stimulated with 100 continuous electrical pulses above threshold, there is a high probability that the maximum number of possible combinations, given by $2^{\mathrm{N}}-1$ will occur.

Ballantyne and Hansen (1974) have introduced a computerized method in which motor units are identified by five parameters: latency, duration, amplitude, area, and number of phases. They stated that 'A given motor unit is likel to differ from every other unit in at least one of these variables'. The results from stimulating $\mathbb{\$}$ motor unit several times at a constant voltage indicate that any of the five parameters cap change for a given motor unit. Thus, if a slight fluctuation in any of the above parameters registered by the computer as the recruitment of an additional unit, then obviously the mean motor unit potential will be low, and the motor unit estimate high. In an attempt to improve upon the original method of McComas et al. (1971), Panayiotopoulos et al. (1974) used photography to discriminate increments within the noise level, which they counted as single motor units. Some of the small variations could have been the result of fluctuations in the amplifier noise and even changes in stimulus artefact. The classification of these fluctuations as small amplitude motor unit action potentials, would give very low MMUP and erroneously high 8 motor unit estimates such as 555 and $599 \gtreqless$ obtained by Panayiotopoulos et al. (1974) for 0 EDB muscles.

2. Are the evoked motor unit action potentials used in the calculation of the mean motor unit potential representative of those generated by the total population of motor units? Single MU isolated during voluntary isometric contractions 
and the $F$ recurrent discharge method have surface potentials which range from less than $100 \mu \mathrm{V}$ to over $1 \mathrm{mV}$. However, the amplitudes of the incremental responses read off directly from a storage oscilloscope rarely exceed $200 \mu \mathrm{V}$. This obviously indicates that the sample of MU used in the estimation of the MMUP is not representative. The modified method I has a wide range of MU amplitudes comparable with the voluntary MU, and is evident by the much larger MMUP $(215 \pm 24 \mu \mathrm{V})$ compared with previous methods (McComas et al., 1971; Ballantyne and Hansen, 1974; Panayiotopoulos et al., 1974; Sica et al., 1974). In the preceding paper, a method was described in which single motor units were obtained by stimulation at multiple locations along the length of the nerve. The amplitudes of the MU isolated by this method ranged from less than $50 \mu \mathrm{V}$ to over $2 \mathrm{mV}$, with mean $\pm \mathrm{SD}$ of $332 \pm 625 \mu \mathrm{V}$. Unfortunately, because there is no built-in correction for the differences in the latencies to peak, the mean amplitude cannot be used directly in the calculation of the MUE. A computerized method is now being devised in this laboratory, which will hopefully solve this problem, and make this method potentially useful for estimating motor unit numbers in the future. In a continuation of this investigation, the two modified methods, and the potentially third method, will be used simultaneously in the estimation of the number of motor units in different muscles in patients with muscular dystrophy.

In conclusion, the authors would like to state that the modified methods described in this paper do not solve all the problems involved in the electrophysiological methods of estimating the number of motor units in a muscle, but should help to make future estimates more accurate. For the present, then, it is necessary to continue to question the validity of the motor unit estimates in health and disease in order to make use more properly of the information such estimates provide.

We gratefully acknowledge financial support from the Muscular Dystrophy Association of Canada; Dr H. S. Milner-Brown is a MDAC Post-doctoral Fellow. We also wish to thank all the hospital and laboratory staff who served as controls, Mrs Liza Morchat for typing the manuscript, and $\mathrm{Mr}$ Stephen Yates for writing the computer programs. Illustrations were by $\mathrm{Mr}$ George Moogk and photography by Mr Michael Donnelly.

\section{REFERENCES}

Ballantyne, J. P., and Hansen, S. (1974). A new method for the estimation of the number of motor units in a muscle. 1. Control subjects and patients with myasthenia gravis. Journal of Neurology, Neurosurgery, and Psychiatry, 37, 907-915.

Bergmans, J. (1970). The Physiology of Single Human Nerve Fibers. Vander: Louvain.

Blair, E. A., and Erlanger, J. (1933). A comparison of the characteristic of axons through their individual electric responses. American Journal of Physiology, 106, 524-564.

Brown, W. F. (1973). Thenar motor unit count estimates in the carpel tunnel syndrome. Journal of Neurology, Neurosurgery, and Psychiatry, 36, 194-198.

Brown, W. F., and Feasby, T. (1974). Estimates of motor axon loss in diabetics. Journal of the Neurological Sciences, 23, 275-293.

Brown, W. F., and Milner-Brown, H. S. (1976). Some electrical properties of motor units and their effects on the methods of estimating motor unit numbers. Journal of Neurology, Neurosurgery, and Psychiatry, 39, 249-257.

McComas, A. J., Fawcett, P. R. W., Campbell, M. T., and Sica, R. E. P. (1971). Electrophysiological estimation of the number of motor units within a human muscle. Journal of Neurology, Neurosurgery, and Psychiatry, 34, 121-131.

Milner-Brown, H. S., Stein, R. B., and Yemm, R. (1973a). The contractile properties of human motor units during voluntary isometric contractions. Journal of Physiology, 228, 285-306.

Milner-Brown, H. S., Stein, R. B., and Yemm, R. (1973b). The orderly recruitment of human motor units during voluntary isometric contractions. Journal of Physiology, 230, 359-370.

Milner-Brown, H. S., Stein, R. B., and Yemm, R. (1973c). Changes in the firing rate of human motor units during linearly changing voluntary contractions. Journal of Physiology, 230, 371-390.

Panayiotopoulos, C. P., Scarpalezos, S., and Papapetropoulos, Th. (1974). Electrophysiological estimation of motor units in Duchenne muscular dystrophy. Journal of Neurological Sciences, 23, 89-98.

Pecher, C. (1939). La fluctuation d'excitabilité de la fibre nerveuse. Archives Internationales de Physiologie et de Biochemie, 49, 129-152.

Sica, R. E. P., McComas, A. J., Upton, A. R. M., and Longmire, D. (1974). Motor unit estimation in small muscles of the hand. Journal of Neurology, Neurosurgery, and Psychiatry, 37, 55-67.

Ten Hoopen, A., and Verveen, A. A. (1963). Nerve-model experiments on fluctuation in excitability. Progress in Brain Research, 2, 8-21.

Verveen, A. A. (1962). Fiber diameter and fluctuation in excitability. Acta Morphologica Neerlands-Scandinavica, 5, 79-85. 